\title{
Cloning and characterization of a gene involved in triacylglycerol biosynthesis and identification of additional homologous genes in the oleaginous bacterium Rhodococcus opacus PD630
}

Correspondence Alexander Steinbüchel steinbu@uni-muenster.de

Received 7 January 2008

Revised 21 April 2008

Accepted 24 April 2008

\author{
Adrian F. Alvarez, ${ }^{2}$ Héctor M. Alvarez, ${ }^{1}$ Rainer Kalscheuer, ${ }^{2}$ \\ Marc Wältermann ${ }^{2}$ and Alexander Steinbüchel ${ }^{2}$
}
${ }^{1}$ Centro Regional de Investigación y Desarrollo Científico Tecnológico (CRIDECIT), Facultad de Ciencias Naturales, Universidad Nacional de la Patagonia San Juan Bosco, Comodoro Rivadavia, Argentina
${ }^{2}$ Institut für Molekulare Mikrobiologie und Biotechnologie der Westfälischen Wilhelms-Universität Münster, Corrensstr. 3, 48149 Münster, Germany

\begin{abstract}
The oleaginous bacterium Rhodococus opacus strain PD630 serves as a model organism to investigate the metabolism of storage triacylglycerols (TAGs) in bacteria. The key enzyme catalysing the last step of TAG biosynthesis in bacteria is a promiscuous acyltransferase (Atf), exhibiting acyl-CoA acyltransferase activity to both diacylglycerols (DGAT activity) and fatty alcohols (wax ester synthase, WS activity). An 800 bp PCR product was obtained from chromosomal DNA of strain PD630 by using degenerate primers designed from conserved stretches of Atf proteins of Acinetobacter baylyi strain ADP1 and Mycobacterium smegmatis $\mathrm{mc}^{2}$ 155. The atf fragment was used as a probe on a strain PD630 gene library, resulting in the identification of a $3948 \mathrm{bp}$ chromosomal DNA fragment containing the complete atf1 gene. An atf1 disruption mutant of strain PD630 exhibited a TAG-leaky phenotype and accumulated up to $50 \%$ less fatty acids than the wild-type, with significantly reduced oleic acid content when cultivated in the presence of gluconate or oleic acid. Whereas DGAT activity was drastically reduced in comparison to the wild-type, WS activity remained almost unchanged in the mutant. RT-PCR analysis of gluconate-grown cells of strain PD630 showed that there is expression of atf1 under conditions of TAG synthesis. To identify additional Atfs in strain PD630, PCR employing non-degenerate primers deduced from Rhodococcus jostii RHA1 sequence data was used. This yielded nine additional atf-homologous genes exhibiting 88-99\% sequence identity to the corresponding strain RHA1 enzymes. Besides Atf1 only Atf2 exhibited high DGAT and/or WS activity when heterologously expressed in Escherichia coli.
\end{abstract}

\section{INTRODUCTION}

Biosynthesis and intracellular accumulation of lipids is widely distributed among animals, plants and microorganisms. Triacylglycerols (TAGs) are the most frequent storage lipids in higher eukaryotes and also in eukaryotic micro-organisms such as yeast, moulds and algae (Christiansen, 1978; Leman, 1997; Ratledge, 1989; Stahmann et al., 1994). In contrast, bacteria usually accumulate specialized lipids such as polyhydroxyalkanoates (Anderson \& Dawes, 1990; Steinbüchel, 1991;

Abbreviations: Atf, acyltransferase; DGAT, diacylglycerol acyltransferase; TAG, triacylglycerol; WE, wax ester; WS, wax ester synthase.

A table of primers and a figure showing a multiple alignment of deduced Atf sequences are available with the online version of this paper.
Steinbüchel \& Valentin, 1995; Alvarez et al., 1997b). The accumulation of large amounts of TAGs in bacteria has been frequently reported in strains belonging to the order Actinomycetales such as Mycobacterium (Barksdale \& Kim, 1977), Streptomyces (Olukoshi \& Packter, 1994; Packter \& Olukoshi, 1995), Nocardia and Rhodococcus (Alvarez et al., 1996, 1997a). Moreover, biosynthesis of wax esters (WEs) has often been reported for Acinetobacter species (Fixter et al., 1986). Biosynthesis of WEs has also been sporadically reported in species of the genera Moraxella (Bryn et al., 1977), Micrococcus (Russell \& Volkman, 1980) and Alcanivorax (Bredemeier et al., 2003). In general, TAGs and WEs are stored as insoluble inclusions of different shapes and sizes inside the cytoplasm, depending on the lipid, strain and culture conditions (Kalscheuer et al., 2001; Wältermann \& Steinbüchel, 2005, 2006) 
Rhodococcus opacus strain PD630 is able to accumulate large amounts of TAGs and under certain culture conditions also minor amounts of WEs; it is one of the best-studied bacteria regarding biosynthesis and accumulation of lipids. Physiological studies analysing the accumulation and mobilization of storage lipids in Rhodococcus sp. showed that TAGs serve as a depot for carbon and energy in these bacteria (Alvarez et al., 2000, 2004; Alvarez \& Steinbüchel, 2002). Strain PD630 can be considered as an oleaginous micro-organism, since TAGs can account for up to 76 or $87 \%$ of the cellular dry weight in gluconate- or olive-oil-grown cells, respectively (Alvarez et al., 1996; Voss \& Steinbüchel, 2001).

Condensation of acyl-CoA and diacylglycerol catalysed by a diacylglycerol-acyltransferase (DGAT or Atf) is the key enzymic step in TAG biosynthesis, since reactions involved in the formation of the diacylglycerol substrate are also part of the phospholipid biosynthesis routes. The first Atf enzyme was described in Acinetobacter baylyi strain ADP1, and it exhibited WE synthase (WS) and DGAT activities (Kalscheuer \& Steinbüchel, 2003). A. baylyi ADP1 possesses only a single Atf enzyme, which is responsible for synthesis of WEs as the main lipid storage compound in addition to minor amounts of TAGs (Kalscheuer \& Steinbüchel, 2003). This enzyme exhibits a high promiscuity with respect to acyl acceptor molecules in vitro (Kalscheuer et al., 2003; Stöveken et al., 2005; Uthoff et al., 2005). This is the reason why it is attracting increasing interest for biotechnological processes, for example 'MicroDiesel' production by recombinant Escherichia coli strains (Kalscheuer et al., 2006a, b). Atf enzymes constitute a heterogeneous family of bacterial acyl-CoA-acyltranferases which do not have significant sequence similarities to eukaryotic DGAT or WS enzymes (Wältermann et al., 2006). The widespread occurrence of atf genes in the genomes of actinomycetes and different Gram-negative bacteria suggests that they play an important role in the life cycle of these organisms (Wältermann \& Steinbüchel, 2006). As an example, Daniel et al. (2004) identified 15 atf-homologous genes in Mycobacterium tuberculosis, which exhibited variable DGAT and WS activity when heterologously expressed in E. coli. Sirakova et al. (2006) suggested that the different sets of atf genes in $M$. tuberculosis are induced in response to different environmental stresses, to enable the organism to synthesize TAGs with maximum efficiency.

Although $R$. opacus PD630 is considered as a model oleaginous prokaryote, the genes involved in TAG biosynthesis and accumulation had not been identified prior to this study. Here we report the characterization of one atf gene and the identification of nine additional putative atf genes from this micro-organism.

\section{METHODS}

Strains, plasmids and growth conditions. $R$. opacus strain PD630 (Alvarez et al., 1996; DSM 44193) and the atf1 mutant derived from it were grown aerobically at $30{ }^{\circ} \mathrm{C}$ in Luria-Bertani (LB) medium
(Sambrook et al., 1989) or in mineral salt medium (MSM) according to Schlegel et al. (1961) with $1 \mathrm{~g} \mathrm{NH}_{4} \mathrm{Cl}^{-1}$ and $1 \mathrm{~g}$ sodium gluconate $1^{-1}$ or $0.1 \%(\mathrm{v} / \mathrm{v})$ oleic acid as carbon source. These conditions are referred to as growth conditions. To promote accumulation of TAGs, $\mathrm{NH}_{4} \mathrm{Cl}$ in MSM was reduced to $0.1 \mathrm{~g} \mathrm{l}^{-1}$ (storage conditions). E. coli strains were cultivated in LB medium at $37^{\circ} \mathrm{C}$. E. coli strains XL1 Blue (Bullock et al., 1987) and S17-1 (Simon et al., 1983) were used for cloning and for conjugational transfer of plasmids to $R$. opacus, respectively. Solid media were prepared by addition of $1.8 \%(\mathrm{w} / \mathrm{v})$ agar-agar. Sucrose sensitivity of $R$. opacus mediated by the $s a c B$ gene was tested on LB agar supplemented with $10 \%$ (w/v) sucrose (LBS). Ampicillin, kanamycin and gentamicin were used at final concentrations of 75,50 or $15 \mu \mathrm{g} \mathrm{ml}^{-1}$, respectively, for recombinant E. coli strains. For Rhodococcus strains, kanamycin and gentamicin were used at final concentrations of $75 \mu \mathrm{g} \mathrm{ml}^{-1}$ or $15 \mu \mathrm{g} \mathrm{ml} \mathrm{m}^{-1}$, respectively. Plasmids used in this study were pBluescript $\mathrm{SK}^{-}$(Stratagene), pGEMT-Easy (Promega), pJQ200mp18 (Quandt \& Hynes, 1993), pHC79 (Hohn \& Collins, 1980) and pSKsym $\Omega K m$ (Overhage et al., 1999).

Isolation, analysis and transfer of DNA. Chromosomal DNA, plasmid DNA and DNA restriction fragments were isolated and analysed by standard methods (Marmur, 1961; Sambrook et al., 1989). Conjugations of E. coli S17-1 harbouring hybrid plasmids (donors) and of Rhodococcus strains (recipients) were performed on solidified LB medium as described by Friedrich et al. (1981). Transformation of $R$. opacus strain PD630 was carried out as described by Kalscheuer et al. (1999).

DNA amplification, cloning and sequencing. For amplification of an $800 \mathrm{bp}$ internal fragment of atf1 from strain PD630, degenerate oligonucleotide primers tgs-int1 (5'-TCSCGCCCGCTSTGGGAG-3') and tgs-int2 (5'-SGGGCCSGGSACGTTCGA-3') were used (Supplementary Fig. S1). The thermocycling parameters were as follows: $5 \mathrm{~min}$ at $94{ }^{\circ} \mathrm{C}, 30$ cycles of $0.5 \mathrm{~min}$ at $94{ }^{\circ} \mathrm{C}, 0.5 \mathrm{~min}$ at $45{ }^{\circ} \mathrm{C}$ and $1 \mathrm{~min}$ at $72{ }^{\circ} \mathrm{C}$, and finally $10 \mathrm{~min}$ at $72{ }^{\circ} \mathrm{C}$. The PCR product was cloned into pGEMT-Easy and subjected to DNA sequencing. Subsequently, the atf1 fragment was DIG-labelled for hybridization analysis and used as a probe on a pBluescript SK-based BamHI-restricted PD630 gene library. For amplification of the complete coding regions of the paralogous atf genes from strain PD630, primers listed in Supplementary Table S1, which were designed based on the sequences of the orthologous genes from Rhodococcus jostii strain RHA1, were used. For cloning of PCR products collinear to the lacZ promoter of pBluescript $\mathrm{SK}^{-}$and effective gene expression, restriction enzyme recognition sites and suitable ribosome-binding sites were incorporated into the oligonucleotide sequences. DNA and deduced protein sequence similarity searches were carried out using BLAST (Altschul et al., 1997). Multiple sequence alignments were done using BioEdit Sequence Alignment Editor (Ibis Biosciences).

Inactivation of atf1 in R. opacus PD630 by gene disruption. Plasmid pJQ200mp18, containing the RP4 origin of transfer for conjugative mobilization and $s a c B$ of Bacillus subtilis for positive selection of double recombination events, was used to construct a mutagenic plasmid for the insertion of a $\Omega \mathrm{Km}$ gene cassette into atf 1 of the strain PD630 chromosome. The $\Omega \mathrm{Km}$ gene cassette, recovered from SmaI-digested pSKsym $\Omega \mathrm{Km}$, was cloned into a unique SmaI

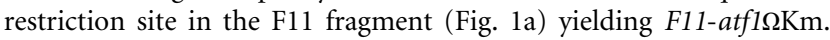
The mutagenic plasmid was constructed by cloning of the BamHI-

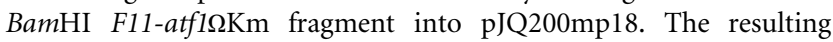

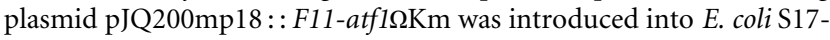
1 and mobilized to $R$. opacus PD630 by conjugation. All resulting $\mathrm{Gm}^{\mathrm{R}}$ and $\mathrm{Km}^{\mathrm{R}} R$. opacus transconjugants were unable to grow after replica plating on LBS agar supplemented with kanamycin and gentamicin $\left(\mathrm{Suc}^{\mathrm{S}}\right)$. The single recombination event was confirmed by 
(a)

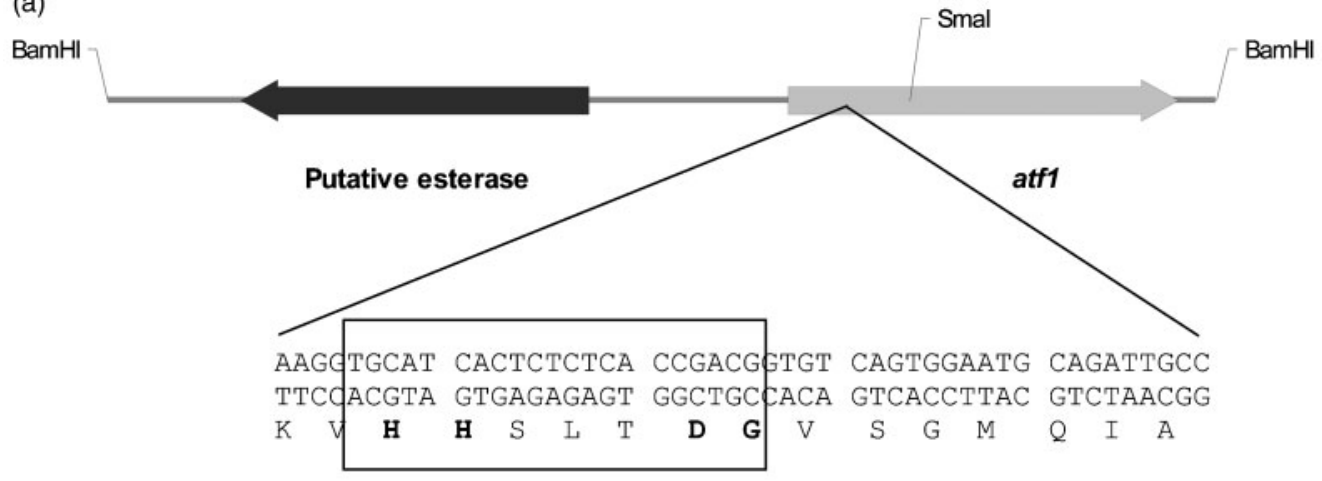

Putative active site

(b)

AtfA ADP1
Atf1
Atf2
Atf3
Atf4
Atf5
Atf6
Atf7
Atf8
Atf9
Atf10

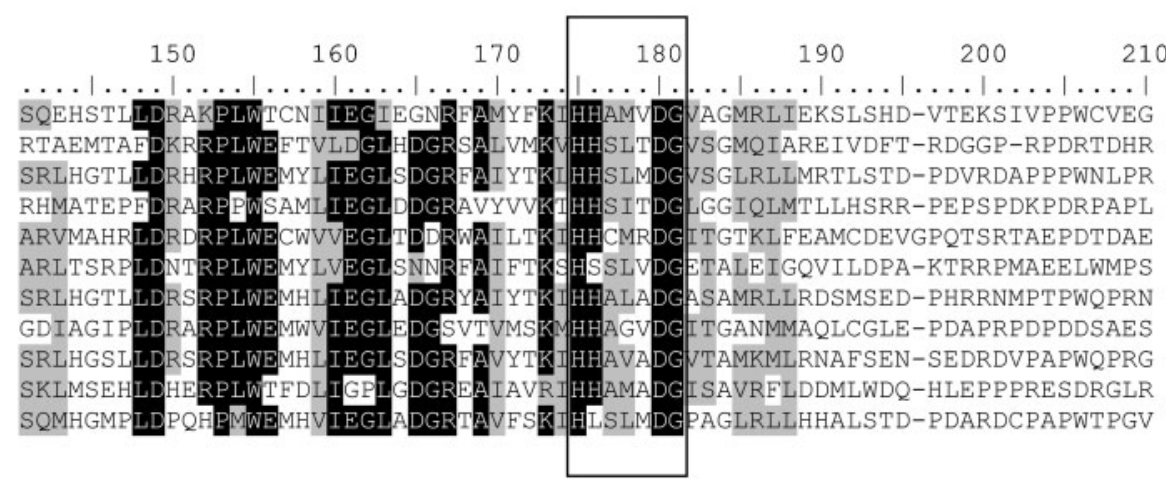

Fig. 1. (a) Molecular organization of the $3948 \mathrm{bp} \mathrm{BamHI}$ restriction fragment of $R$. opacus strain PD630 chromosomal DNA (fragment F11) harbouring the atf1 gene. The sequence of the region of atf1 that contains the putative active site is shown. (b) Multiple sequence alignment of the regions constituting the suggested active sites of Atf proteins from $R$. opacus PD630 with the AtfA protein from A. baylyi strain ADP1. Conserved amino acids are shaded in black, and homologous residues in grey. The putative active site is boxed.

Southern blot analysis (not shown). Gene inactivation of atf1 was achieved by overnight culture of transconjugants under non-selective conditions and subsequent plating on LBS containing $75 \mu \mathrm{g}$ kanamycin $\mathrm{ml}^{-1}$. The $\mathrm{Suc}^{\mathrm{R}} / \mathrm{Km}^{\mathrm{R}}$ colonies were replica plated on LBS plates containing gentamicin plus kanamycin and on LBS plates with only kanamycin. $\mathrm{Gm}^{\mathrm{S}} / \mathrm{Km}^{\mathrm{R}}$ colonies were taken for subsequent PCR assays, using the primers listed in Supplementary Table S1 for atf1, and Southern blot analysis was done to confirm disruption of the atfl gene (data not shown).

Lipid analysis. The qualitative and semiquantitative analyses of intracellular lipids in R. opacus PD630 were carried out by thin-layer chromatography (TLC). For this, $1 \mathrm{mg}$ of lyophilized cells was extracted with $200 \mu \mathrm{l}$ chloroform/methanol $(2: 1, \mathrm{v} / \mathrm{v})$ for $30 \mathrm{~min}$. The supernatant was then concentrated and subjected to silica G TLC as previously described, using hexane/diethyl ether/acetic acid $(80: 20: 1$, by vol.) as solvent for TAG analysis (Wältermann et al., 2000). Triolein and oleyl oleate were used as TAG and WE reference substances, respectively.

Fatty acid analysis of whole cells or purified TAGs was done by gas chromatography (GC) according to Kalscheuer et al. (2004). For this, 3-5 mg of lyophilized cells was subjected for $4 \mathrm{~h}$ to methanolysis at $100{ }^{\circ} \mathrm{C}$ in the presence of $15 \%(\mathrm{v} / \mathrm{v})$ sulphuric acid suspended in methanol. The resulting fatty acid methyl esters were analysed on an Agilent 6850 gas chromatograph equipped with a BP21 capillary column (50 m × $0.22 \mathrm{~mm}$; film thickness $250 \mathrm{~nm}$ ) (SGE, Darmstadt, Germany) and a flame-ionization detector (Agilent Technologies). A $2 \mu \mathrm{l}$ portion of the organic phase was analysed after split injection; hydrogen (constant flow of $0.6 \mathrm{ml} \mathrm{min}{ }^{-1}$ ) was used as a carrier gas. The temperatures of the injector and detector were 250 and $275{ }^{\circ} \mathrm{C}$, respectively. The following temperature programme was applied: $120{ }^{\circ} \mathrm{C}$ for $5 \mathrm{~min}$, increase of $3{ }^{\circ} \mathrm{C} \min ^{-1}$ to $180{ }^{\circ} \mathrm{C}$, increase of $10{ }^{\circ} \mathrm{C}$ $\min ^{-1}$ to $220{ }^{\circ} \mathrm{C}$, and $220{ }^{\circ} \mathrm{C}$ for $31 \mathrm{~min}$. Substances were identified by comparison of their retention times with those of standard fatty acid methyl esters.

Determination of enzyme activities. Cells of $R$. opacus were incubated overnight under storage conditions, whereas for heterologous expression, recombinant E. coli were cultivated for $6 \mathrm{~h}$ in the presence of $1 \mathrm{mM}$ IPTG. Cells were then harvested and broken using a French press, and the resulting crude extracts were used for enzyme activity determination. WS and DGAT activities were determined in a total volume of $250 \mu \mathrm{l}$ containing $12.5 \mu \mathrm{g} \mathrm{BSA} \mathrm{ml} \mathrm{m}^{-1}, 4.72 \mu \mathrm{M}$ $\left[1-{ }^{14} \mathrm{C}\right]$ palmitoyl-CoA (specific activity, $1.961 \mathrm{~Bq} \mathrm{pmol}^{-1}$ ), $125 \mathrm{mM}$ sodium phosphate buffer ( $\mathrm{pH} 7.4$ ), and $3.75 \mathrm{mM}$ 1-hexadecanol or 1,2-dipalmitoylglycerol. Water-insoluble substrates and BSA were applied as double-concentrated stock solutions emulsified by 
ultrasonification. The assay mixtures were incubated for $30 \mathrm{~min}$ at $35{ }^{\circ} \mathrm{C}$, and the reactions were stopped by extraction with $500 \mu \mathrm{l}$ chloroform/methanol $(1: 1, \mathrm{v} / \mathrm{v})$. After centrifugation, the chloroform phase was withdrawn and evaporated to dryness, and $40 \mu \mathrm{g}$ of unlabelled reference substances was added. The reaction products were separated by TLC using the solvent systems hexane/diethyl ether/acetic acid (90:7.5:1, by vol.) and hexane/diethyl ether/acetic acid $(80: 20: 1$, by vol.). After separation of lipids and their staining with iodine vapour, spots corresponding to the reaction products were scraped from the plates, and radioactivity was measured by scintillation counting.

RNA isolation and RT-PCR. Total RNA was extracted from cells of $R$. opacus PD630 at different growth phases by three breaking cycles (1 min of breaking at maximal speed, 1 min on ice) on a Mini-Bead Beater in the presence of $0.1 \mathrm{~mm}$ glass beads. RNA was purified using the RNeasy Miniprep kit (Qiagen) and treated with DNase I (RNaseFree DNase Set, Qiagen). Total RNA $(1 \mu \mathrm{g})$ served as template in a one-step RT-PCR using the following internal primers: $5^{\prime}$ AGATCGTGGATTTCACCCGCGATG-3' (Tag1-RT-PCRup) and 5'CGTCATCCGCAGTTCGCTGAT-3' (Tag1-RTPCRdown) for atf1; 5'-GATGCGGACGCTGTCGACCGA-3' (Tag2-RTPCRup) and 5'GGCGTCGGCCTTCTGCTCGTC-3' (Tag2-RTPCRdown) for atf2. The thermocycling programme of the one-step PCR consisted of a reverse transcription at $50{ }^{\circ} \mathrm{C}$ for $30 \mathrm{~min}$, an initial denaturation at $95{ }^{\circ} \mathrm{C}$ for $15 \mathrm{~min}, 30-35$ cycles (denaturation at $94{ }^{\circ} \mathrm{C}$ for $30 \mathrm{~s}$, annealing at $55{ }^{\circ} \mathrm{C}$ for $30 \mathrm{~s}$, and elongation at $72{ }^{\circ} \mathrm{C}$ for $60 \mathrm{~s}$ ), and a final 10 min elongation at $72{ }^{\circ} \mathrm{C}$. PCR products were subjected to electrophoresis on a $1.2 \%$ agarose gel.

\section{RESULTS}

\section{Identification of a DNA fragment containing a gene involved in TAG synthesis in $R$. opacus PD630}

The sequences of the AtfA protein from A. baylyi ADP1 (accession number AAO17391) and seven homologous proteins from Mycobacterium smegmatis $\mathrm{mc}^{2} 155$ (accession numbers ABK74273, ABK70911, ABK69671, ABK70404, $A B K 69832, A B K 75217$ and ABK71433) were aligned, and two short conserved sequences were selected for design of degenerate primers according to the codon usage of $R$. opacus. An $800 \mathrm{bp}$ fragment exhibiting regions with high similarities to atfA of $A$. baylyi ADP1 was amplified by PCR from chromosomal DNA of $R$. opacus PD630 as a template. To obtain the whole putative $R$. opacus atf gene, the fragment was used as a probe in a Southern blot hybridization assay employing $B a m H-$ restricted chromosomal DNA from $R$. opacus, yielding a single hybridizing fragment of approx. $4 \mathrm{kbp}$ (not shown). A partial library of BamHI-restricted $R$. opacus chromosomal DNA in plasmid pBluescriptSK ${ }^{-}$was constructed in E. coli and investigated by dot-blot hybridization assays. One clone (F11), harbouring the desired $3948 \mathrm{bp}$ fragment, was isolated. Fragment F11 contained two complete ORFs in opposite directions: a TAG-synthase-homologous gene (atfl) and a putative esterase gene (Fig. 1a). The amino acid sequence deduced from atf1 shared conserved sequences, including the putative active-site motif HHxxxDG, with the AtfA protein from A. baylyi strain ADP1 and other reported Atf enzymes. However, the Atf1 amino acid sequence showed the highest similarity $(89 \%$ identity) to a predicted protein of $R$. jostii strain RHA1 (accession number YP_700033) (Table 1).

\section{Construction and characterization of the disruption mutant $R$. opacus atf1 $\Omega \mathrm{Km}$}

An atf1 knockout mutant was constructed by a double recombination strategy using the counter-selectable marker $s a c B$ as described in Methods. To compare the atf 1 knockout mutant and the wild-type for their abilities to accumulate TAGs, the two strains were cultivated under both storage and growth conditions. As revealed by TLC, the disrupted atfl mutant was still able to synthesize TAGs after incubation under storage conditions; however, diminished amounts of TAGs were accumulated in the cells (Fig. 2a). Quantitative and qualitative GC analysis of cells cultivated under growth conditions revealed that the mutant strain atf $1 \Omega \mathrm{Km}$ contained up to $50 \%$ less total fatty acids during stationary phase (after $36 \mathrm{~h}$ ) compared to the wild-type (Fig. 2b). Interestingly, the relative proportion of oleic acid (C18:1) in crude cell masses and also in TAG samples purified from the cells was generally lower in the mutant (Fig. 3a-c). The relative amount of C18:1 in the cell mass and in TAG samples of mutant cells decreased to as low

Table 1. Identities of Atf1 from R. opacus PD630 to different Atf-homologous proteins

\begin{tabular}{|lclccl|}
\hline Strain & $\begin{array}{c}\text { No. of Atf1 } \\
\text { homologues }\end{array}$ & \multicolumn{1}{c}{ Protein } & Length (aa) & $\begin{array}{c}\text { Identity to Atf1 } \\
\text { (\%) } \dagger\end{array}$ & Accession no. $\neq$ \\
\hline Acinetobacter baylyi ADP1 & 1 & AtfA & 458 & 24 & AAO17391 \\
Mycobacterium smegmatis $\mathrm{mc}^{2}$ 155 & 8 & MSMEG_3933 & 451 & 35 & YP_888223 \\
Mycobacterium tuberculosis H37Rv & 15 & Rv2484c & 491 & 29 & NP_217000 \\
Rhodococcus jostii RHA1 & 14 & RO00039 & 473 & 89 & YP_700033 \\
Streptomyces coelicolor A3(2) & 3 & SCO1280 & 413 & 23 & NP_625567 \\
Alcanivorax borkumensis SK2 & 2 & AtfA1 & 451 & 20 & YP_693524 \\
\hline
\end{tabular}

*Protein with the highest identity to the Atf1 protein from R. opacus PD630.

$\dagger$ Identities were based on alignments of primary protein structure derived from full-length gene sequences.

\$Accession numbers in the NCBI protein database. 
(a)

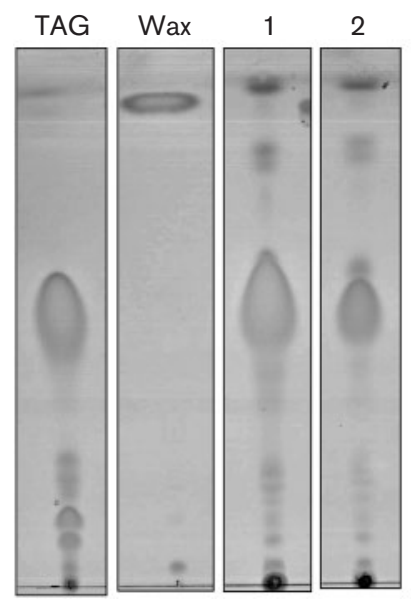

(b)

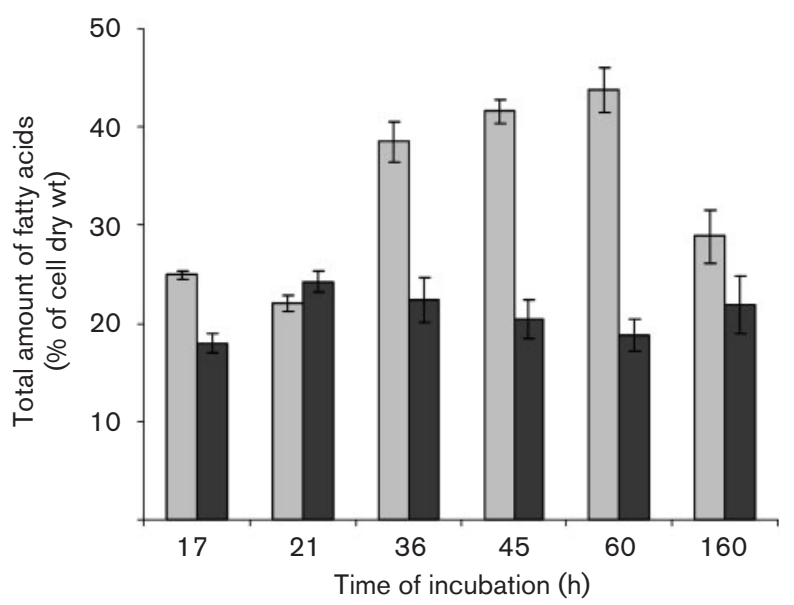

Fig. 2. Lipid analysis of whole-cell extracts of $R$. opacus strains grown with gluconate as carbon source. (a) TLC. Lanes: TAG, TAG standard; Wax, wax standard; 1, wild-type $R$. opacus PD630; 2, mutant $R$. opacus atf1 $\Omega \mathrm{Km}$; the cells were grown in LB medium for $24 \mathrm{~h}$, harvested, washed and then incubated for $17 \mathrm{~h}$ under storage conditions. (b) Total amounts of fatty acids of atf1 mutant strain (dark grey bars) in comparison to the wild-type (light grey bars) in different growth stages; the cells were grown in MSM (growth conditions). The data represent the means of two independent experiments. Error bars indicate the range of results.

as $50 \%$ of that of the wild-type cells grown in presence of oleic acid. The relative amounts of palmitoleic acid (C16:1) in cell dry mass and in TAG samples of the mutant cells grown under these conditions were also significantly lower in comparison to the wild-type (Fig. 3b, c).

The WS and DGAT activities in wild-type and mutant cells incubated under storage conditions with sodium gluconate as carbon source were measured. Whereas the DGAT activity in the mutant decreased to about one-third $\left[62.2 \pm 8.6 \mathrm{pmol}(\mathrm{mg} \mathrm{min})^{-1}\right]$ of the respective activity in the parental strain $\left[169.0 \pm 10.4 \mathrm{pmol}\left(\mathrm{mg} \mathrm{min}^{-1}\right]\right.$, the WS activity in the knockout mutant did not show a significant decrease [from $79.9 \pm 13.6 \mathrm{pmol}(\mathrm{mg} \mathrm{min})^{-1}$ in the wildtype to $65.0 \pm 2.3 \mathrm{pmol}(\mathrm{mg} \mathrm{min})^{-1}$ in the mutant].

\section{Identification of other atf1-homologous genes in $R$. jostii strain RHA1 and $R$. opacus strain PD630}

The only sequenced genome of a species of the genus Rhodococcus is that of $R$. jostii strain RHA1 (McLeod et al., 2006). The $R$. jostii RHAl genome data at Canada's Michael Smith Genome Sciences Centre (http:// www.bcgsc.ca) were analysed for the occurrence of atf1homologous genes. Fourteen genes whose products have significant amino acid identity $(>22 \%)$ to the Atf1 protein from $R$. opacus PD630 were identified in this strain. Three of these genes were located on the linear megaplasmid pRHL1 (YP_707847, YP_707571, YP_707862); the third of these three genes was a truncated form of the first one. The deduced amino acid sequences of all 11 chromosomal atf1homologous genes exhibited the conservative active-site motif HHxxxDG and also other consensus sequences. One of these genes (YP_700033) and its flanking regions shared about $90 \%$ nucleotide identity with the atf 1 gene of strain PD630 and with the complete F11 fragment.

The analysis of the atf1 mutant provided clear evidence that further Atfs are present in R. opacus strain PD630. To amplify as many of the additional atf genes as possible from $R$. opacus PD630, and taking the high sequence homology and the phylogenetic relationship between strains RHA1 and PD630 into account, non-degenerate primers, according to the 10 remaining chromosomal atf-homologous genes found in the RHAl genome, were constructed (Supplementary Table S1). By applying these primers, nine further atf-homologous genes were successfully amplified (atf2 to atf10). All deduced amino acid sequences possess the complete putative active-site motif HHxxxDG described for bacterial Atf proteins. Those of Atf5 and Atf10 exhibited a modified active-site motif, in which the second histidine was replaced by serine or lysine, respectively (Fig. $1 \mathrm{~b}$ and Supplementary Fig. S1). As a particular case, the atf2 gene exhibited a premature stop-codon due to a point mutation in position 1107, thereby yielding a protein of only 374 instead of 453 amino acids in the RHA1 protein. This gene was amplified twice to confirm this observation and to exclude a mistake during PCR amplification.

The deduced amino acid sequences of the 10 putative Atf proteins of strain PD630 were analysed with the transmembrane prediction program DAS (Cserzö et al., 1997). Eight Atf proteins of strain PD630 possessed at least one putative transmembrane region which may permit proteins 

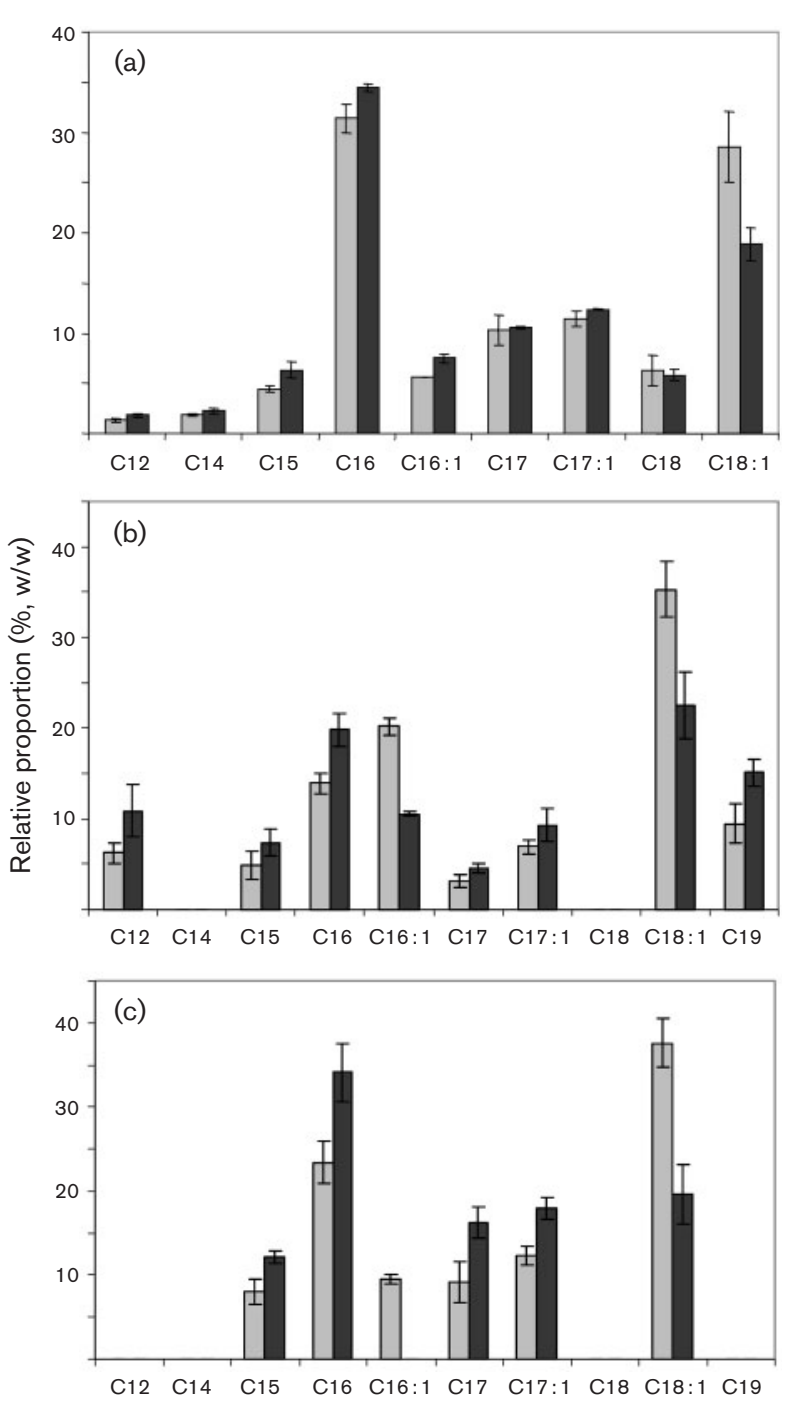

Fig. 3. Fatty acid composition of $R$. opacus PD630 (light grey bars) and $R$. opacus atf $1 \Omega \mathrm{Km}$ (dark grey bars) incubated under storage conditions. (a) Whole-cell extracts from cells incubated in MSM containing gluconate as carbon source; (b) whole-cell extracts from cells incubated in MSM containing oleic acid as carbon source; (c) TAG fraction from extracts of cells incubated as in (b). The data represent the means of two independent experiments. Error bars indicate the range of results.

to anchor to a phospholipid membrane. Atf1 possesses two putative transmembrane domains, as shown in Fig. 4(a). Only Atf2 and Atf6 seemed to be cytoplasmic enzymes without a predicted membrane-spanning region (Fig. 4b).

\section{Heterologous expression of atf genes from R. opacus PD630}

The 10 putative atf genes from $R$. opacus PD630 were amplified by tailored PCR introducing a ribosome-binding site and were cloned into pBluescript $\mathrm{SK}^{-}$collinear to the lacZ promoter. After transfer of plasmids to E. coli XL1
Blue, expression of all putative atf genes was demonstrated by SDS-PAGE (data not shown). To reveal whether the synthesized proteins exhibit WS and DGAT activities, crude protein extracts of the recombinant strains were analysed for their acyltransferase activities (Table 2). In general, all crude extracts of recombinant E. coli strains exhibited only low enzymic activities compared to those obtained from the $R$. opacus strains used in this study. Although atf1 seemed to be responsible for a significant part of the TAG accumulation in strain PD630, as was concluded from the gene-disruption experiment, the atf1 gene product exhibited almost no DGAT activity when expressed in recombinant E. coli. Interestingly, Atf1 exhibited significant WS activity. In contrast, recombinant E. coli harbouring plasmid pBluescriptSK:: atf2 exhibited WS as well as significant DGAT activities. However, crude protein extracts of E. coli strains expressing atf3 to atf10 exhibited no or only slightly increased WS/DGAT activities in comparison to the vector control cultivated under conditions used in this study (Table 2).

\section{In vivo expression of atf genes in $R$. opacus PD630}

Since the atf1 and atf2 gene products showed the highest acyltransferase activities when expressed in recombinant $E$. coli, their expression in cells of $R$. opacus PD630 from different stages of growth and TAG accumulation was investigated by RT-PCR. For this, cells were grown in MSM containing gluconate, allowing accumulation of TAGs, and cell samples for RNA isolation were withdrawn in the early $(14 \mathrm{~h})$ and the late $(21 \mathrm{~h})$ exponential growth phase. In addition, samples from cells of the stationary growth phase (45 h), which had accumulated large amounts of TAGs, were taken and subjected to RNA isolation. Transcripts of both atf1 and atf2 genes were detected in all cells harvested at the indicated growth phases (Fig. 5).

\section{DISCUSSION}

The present study was undertaken to identify genes involved in the key step of TAG biosynthesis in the oleaginous bacterium R. opacus strain PD630. A 3948 bp chromosomal DNA fragment of strain PD630 harbouring the atf1 gene was identified after degenerate PCR and dotblot hybridization experiments. The Atf1 protein contained the putative active-site motif $\mathrm{HHxxxDG}$ as well as other conserved regions which are typically also present in related proteins from $A$. baylyi ADP1, M. smegmatis $\mathrm{mc}^{2} 155$ and $M$. tuberculosis (Kalscheuer \& Steinbüchel, 2003; Daniel et al., 2004).

An atf1 knockout mutant was constructed using the $s a c B$ gene as a counter-selectable marker against single crossover events (Jäger et al., 1995; Pelicic et al., 1996; Ramakrishnan et al., 1997). The disruption of the atf1 gene resulted in a significant decrease of the total fatty acids (up to $50 \%$ ) as well as of the cellular TAG content, as shown by TLC 


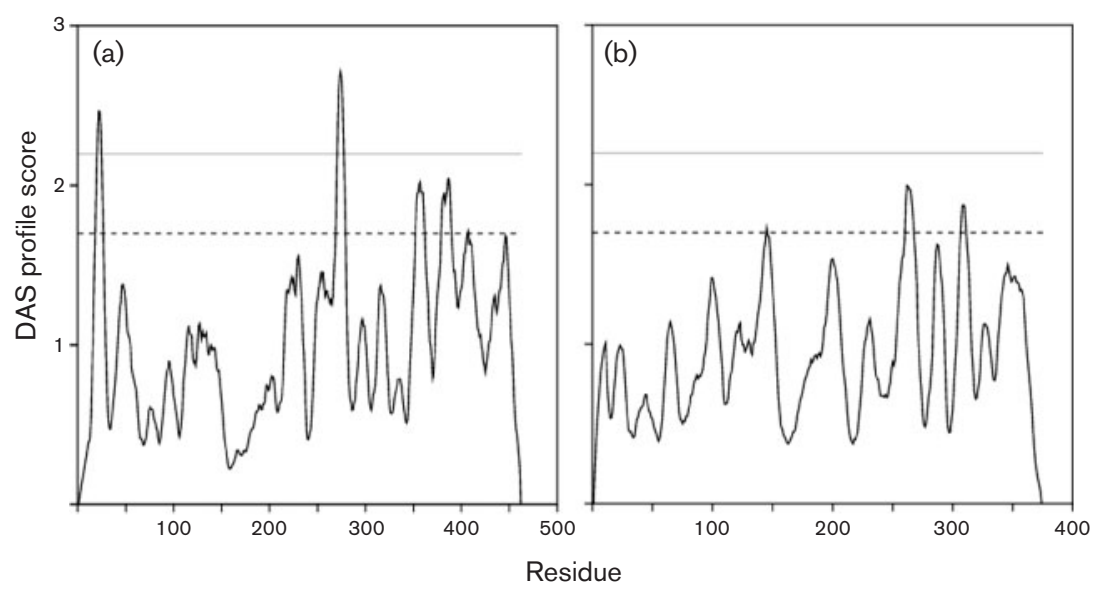

Fig. 4. Hydrophobicity plot 'DAS' transmembrane (TM) segment prediction of (a) Atf1 and (b) Atf2. The dashed line indicates a loose cutoff, whereas the line at 2.2 DAS score corresponds to a strict cutoff for TM segment prediction. Only Atf6 showed a plot similar to Atf2 without putative TM regions. All other Atf paralogues of PD630 possessed at least one putative TM region as shown in the DAS plot of Atf1. analysis, and also in a substantial reduction of DGAT activity in crude extracts; on this basis, Atf1 could be considered as a major enzyme for lipid biosynthesis in $R$. opacus PD630. However, this must be further confirmed by analysis of a complemented mutant strain. Furthermore, the mutant exhibited a modified fatty acid profile, with reduced relative amounts of oleic and palmitoleic acids. The same pattern was observed with fatty acids from both whole-cell extracts and TAG fractions. These results indicate that other TAG-synthesizing enzymes beside Atf1, with different substrate specificities, contribute to the total DGAT activity and TAG accumulation in strain PD630, as was also shown in the pathogenic M. tuberculosis (Daniel et al., 2004). The M. tuberculosis genome encodes 15 putative TAG synthases (Tgs), and disruption of the $\operatorname{tgs} 1$ gene in this bacterium reduced TAG accumulation drastically under conditions of hypoxia or acidic environment, or upon treatment with NO (Sirakova et al., 2006). These results suggest that $\operatorname{tgs} 1$ in M. tuberculosis is a major contributor to TAG synthesis under the mentioned

Table 2. WS and DGAT activities in crude extracts of recombinant $E$. coli $\mathrm{XL1}$ Blue containing atf genes from $R$. opacus PD630

\begin{tabular}{|c|c|c|}
\hline Strain & $\begin{array}{c}\text { DGAT activity } \\
{\left[\text { pmol }(\mathrm{mg} \mathrm{min})^{-1}\right]}\end{array}$ & $\begin{array}{l}\text { WS activity }{ }^{*}[\mathrm{pmol} \\
\left.\quad(\mathrm{mg} \mathrm{min})^{-1}\right]\end{array}$ \\
\hline XL1 Blue pSK ${ }^{-}$ & $0.22 \pm 0.04$ & $0.19 \pm 0.01$ \\
\hline XL1Blue pSK::atf1 & $0.37 \pm 0.09$ & $4.65 \pm 0.04$ \\
\hline XL1Blue pSK::atf2 & $7.19 \pm 0.15$ & $4.02 \pm 0.44$ \\
\hline XL1Blue pSK::atf3 & $0.07 \pm 0.01$ & $0.08 \pm 0.03$ \\
\hline XL1Blue pSK:: atf4 & $0.48 \pm 0.09$ & $0.31 \pm 0.08$ \\
\hline XL1Blue pSK:: atf5 & $0.42 \pm 0.01$ & $0.39 \pm 0.08$ \\
\hline XL1Blue pSK::atf6 & $0.44 \pm 0.04$ & $0.42 \pm 0.07$ \\
\hline XL1Blue pSK:: atf7 & $0.19 \pm 0.05$ & $0.08 \pm 0.03$ \\
\hline XL1Blue pSK::atf8 & $0.08 \pm 0.01$ & $0.10 \pm 0.02$ \\
\hline XL1Blue pSK:: atf9 & $0.10 \pm 0.04$ & $0.08 \pm 0.02$ \\
\hline XL1Blue pSK: : atf10 & $0.09 \pm 0.01$ & $0.08 \pm 0.01$ \\
\hline
\end{tabular}

*Values are means \pm SD of at least two independent experiments. conditions. Interestingly, the authors demonstrated that Tgs1 preferred C26:0-CoA for TAG biosynthesis (Sirakova et al., 2006). C26:0 was the major fatty acid in the TAGs stored under stress; however, this fatty acid was absent even in the very small amounts of TAG produced by the tgs1deficient mutant. A change in the fatty acid pattern was also described in a DGAT mutant (AS11) of the higher plant Arabidopsis thaliana; this mutant, which is characterized by a reduced amount of storage lipid in mature seeds, showed an increased accumulation of linoleic acid $(\mathrm{C} 18: 3)$ as the major fatty acid and reduced levels of C18:1 incorporation in comparison to the wild-type (Katavic et al., 1995). Changes in the fatty acid profiles of accumulated TAGs in Atf mutants may therefore indicate that in actinomycetes Atf isoenzymes are specialized for the selective incorporation of different fatty acyl residues into TAGs.

Enzymes which accomplish the last step of TAG or WE biosynthesis in bacteria exhibit high sequence variability. The $R$. opacus Atf1 exhibits only around 30\% sequence similarity to other Atf proteins known so far. Based on sequence alignments, we have identified 11 additional homologous genes in the chromosome of $R$. jostii strain RHA1, and one of these showed an unusually high sequence identity. By using oligonucleotides designed on the basis of strain RHA1 homologous genes, nine further genes (atf2 to atf10) encoding putative Atf enzymes exhibiting 88-99\% sequence identity to strain RHAl genes were amplified from $R$. opacus PD630 DNA and were subsequently cloned. However, only atf1 and atf2 exhibited high WS and/or DGAT activity in vitro, indicating that these genes encode functional WS/DGAT enzymes. Similar results were reported by Daniel et al. (2004) for $M$. tuberculosis. Among the 15 Tgs proteins in this bacterium, only four exhibited high DGAT activity when expressed in E. coli. Since the sequence data do not provide evidence that these genes encode functionally inactive enzymes, the substrate range of these enzymes may be quite different and they may not react with the routinely used substrates of $\mathrm{C}_{16}$ chain length. In addition, heterologous expression of genes 


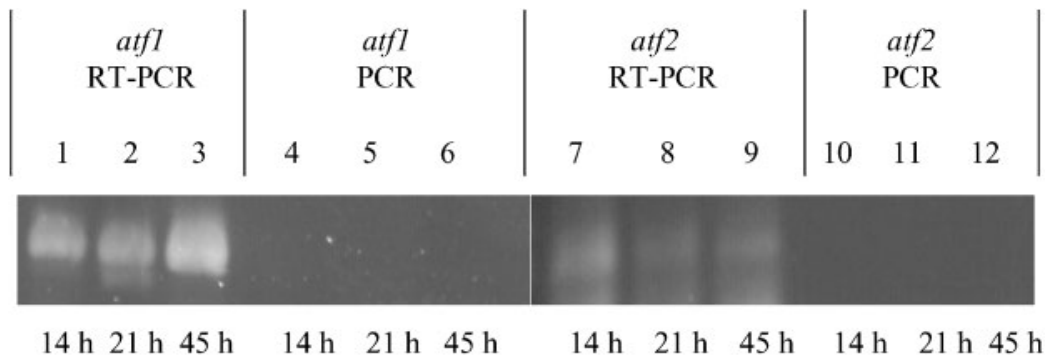

Fig. 5. Agarose gel electrophoresis of RTPCR products of atf1 and atf2. Lanes 1-3, $450 \mathrm{bp}$ fragments of atf1 amplified from RNA from strain PD630 at different incubation times; lanes 4-6, negative control. Lanes 79, $460 \mathrm{bp}$ fragments of atf2 amplified from RNA from strain PD630 at different incubation times; lanes 10-12, negative control.

from $R$. opacus in E. coli could yield incorrectly folded proteins that do not reflect their activities in vivo.

Most of the 10 Atfs from $R$. opacus seem to be transmembrane proteins, as revealed by the TM prediction program. By applying immunogold labelling, Stöveken et al. (2005) showed AtfA from A. baylyi ADP1 to be associated with the cytoplasmic membrane as well as with lipid inclusions and to occur also in soluble form in the cytoplasm. Nevertheless, as strain PD630 possesses multiple paralogous proteins, the exact cellular distribution of the Atf proteins must be determined by further studies.

RT-PCR analysis revealed that the atf1 and atf 2 genes were transcribed during all stages of growth and TAG accumulation under the conditions used in this study. The occurrence of at least 10 genes encoding putative Atf enzymes in $R$. opacus PD630 suggests a key role of these enzymes for the physiology of this soil micro-organism and probably for its ability to cope with diverse environmental stresses. However, evidence for the existence of an as yet unknown alternative TAG biosynthesis route was recently found in Alcanivorax borkumensis (Kalscheuer et al., 2007), and as yet unknown types of TAG-synthesizing enzymes may also occur in other TAG-accumulating bacteria such as R. opacus PD630.

\section{ACKNOWLEDGEMENTS}

A.F.A. is indebted to the Deutsche Akademischer Austauschdienst (DAAD) for the award of a doctoral scholarship. H. M. A. is a career investigator of the Consejo Nacional de Investigaciones Científicas y Técnicas (CONICET), Argentina.

\section{REFERENCES}

Altschul, S. F., Madden, T. L., Schäffer, A. A., Zhang, J., Zhang, Z., Miller, W. \& Lipman, D. J. (1997). Gapped BLAST and PSI-BLAST: a new generation of protein database search programs. Nucleic Acids Res 25, 3389-3402.

Alvarez, H. M. \& Steinbüchel, A. (2002). Triacylglycerols in prokaryotic microorganisms. Appl Microbiol Biotechnol 60, 367-376.

Alvarez, H. M., Mayer, F., Fabritius, D. \& Steinbüchel, A. (1996). Formation of intracytoplasmatic lipid inclusions by Rhodococcus opacus strain PD630. Arch Microbiol 165, 377-386.

Alvarez, H. M, Kalscheuer, R. \& Steinbüchel, A. (1997a). Accumulation of storage lipids in species of Rhodococcus and
Nocardia and effect of inhibitors and polyethylene glycol. Fett 99, 239-246.

Alvarez, H. M., Pucci, O. H. \& Steinbüchel, A. (1997b). Lipid storage compounds in marine bacteria. Appl Microbiol Biotechnol 47, 132-139.

Alvarez, H. M., Kalscheuer, R. \& Steinbüchel, A. (2000). Accumulation and mobilization of storage lipids by Rhodococcus opacus PD630 and Rhodococcus ruber NCIMB 40126. Appl Microbiol Biotechnol 54, 218-223.

Alvarez, H. M., Silva, R. A., Cesari, A. C., Zamit, A. L., Peressutti, S. R., Reichelt, R., Keller, U., Malkus, U., Rasch, C. \& other authors (2004). Physiological and morphological responses of the soil bacterium Rhodococcus opacus strain PD630 to dehydration. FEMS Microbiol Ecol 50, 75-86.

Anderson, A. J. \& Dawes, E. A. (1990). Occurrence, metabolism, metabolic role and industrial uses of bacterial polyhydroxyalkanoates. Microbiol Rev 54, 450-472.

Barksdale, L. \& Kim, K. S. (1977). Mycobacterium. Bacteriol Rev 41, 217-372.

Bredemeier, R., Hulsch, R., Metzger, J. O. \& Berthe-Corti, L. (2003). Submersed culture production of extracellular wax esters by the marine bacterium Fundibacter jadensis. Mar Biotechnol (NY) 5, 579-583.

Bryn, K., Jantzen, E. \& Bovre, K. (1977). Occurrence and patterns of waxes in Neisseriaceae. J Gen Microbiol 102, 33-43.

Bullock, W. O., Fernandez, J. M. \& Stuart, J. M. (1987). XL1-Blue: a high efficiency plasmid transforming recA Escherichia coli strain with $\beta$-galactosidase selection. Biotechniques 5, 376-379.

Christiansen, K. (1978). Triacylglycerol synthesis in lipid particles from baker's yeast (Saccharomyces cerevisiae). Biochim Biophys Acta 530, 78-90.

Cserzö, M., Wallin, E., Simon, I., von Heijne, G. \& Elofsson, A. (1997). Prediction of transmembrane alpha-helices in prokaryotic membrane proteins: the dense alignment surface method. Protein Eng 10, 673-676.

Daniel, J., Deb, C., Dubey, V. S., Sirakova, T. D., Abomoelak, B., Morbidoni, H. R. \& Kolattukudy, P. E. (2004). Induction of a novel class of diacylglycerol acyltransferases and triacylglycerol accumulation in Mycobacterium tuberculosis as it goes into a dormancy-like state in culture. J Bacteriol 186, 5017-5030.

Fixter, L. M., Nagi, M. N., McCormack, J. G. \& Fewson, C. A. (1986). Structure, distribution and function of wax esters in Acinetobacter calcoaceticus. J Gen Microbiol 132, 3147-3157.

Friedrich, B., Hogrefe, C. \& Schlegel, H. G. (1981). Naturally occurring genetic transfer of hydrogen-oxidizing ability between strains of Alcaligenes eutrophus. J Bacteriol 147, 198-205.

Hohn, B. \& Collins, J. (1980). A small cosmid for efficient cloning of large DNA fragments. Gene 11, 291-298.

Jäger, W., Schäfer, A., Kalinowski, J. \& Pühler, A. (1995). Isolation of insertion elements from Gram-positive Brevibacterium, Corynebacterium and Rhodococcus strains using the Bacillus subtilis $s a c B$ gene as a positive selection marker. FEMS Microbiol Lett 126, 1-6. 
Kalscheuer, R. \& Steinbüchel, A. (2003). A novel bifunctional wax ester synthase/acyl-CoA: diacylglycerol acyltransferase mediates wax ester and triacylglycerol biosynthesis in Acinetobacter calcoaceticus ADP1. J Biol Chem 278, 8075-8082.

Kalscheuer, R., Arenskötter, M. \& Steinbüchel, A. (1999). Establishment of a gene transfer system for Rhodococcus opacus PD630 based on electroporation and its application for recombinant biosynthesis of poly(3-hydroxyalkanoic acids). Appl Microbiol Biotechnol 52, 508-515.

Kalscheuer, R., Wältermann, M., Alvarez, H. M. \& Steinbüchel, A. (2001). Preparative isolation of lipid inclusion bodies from Rhodococcus opacus and Rhodococcus ruber and identification of granule-associated proteins. Arch Microbiol 177, 20-28.

Kalscheuer, R., Uthoff, S., Luftmann, H. \& Steinbüchel, A. (2003). In vitro and in vivo biosynthesis of wax diesters by an unspecific bifunctional wax ester synthase/acyl-CoA : diacylglycerol acyltransferase (WS/DGAT) from Acinetobacter calcoaceticus ADP1. Eur J Lipid Sci Technol 105, 578-584.

Kalscheuer, R., Luftmann, H. \& Steinbüchel, A. (2004). Synthesis of novel lipids in Saccharomyces cerevisiae by heterologous expression of an unspecific bacterial acyltransferase. Appl Environ Microbiol 70, 7119-7125.

Kalscheuer, R., Stölting, T. \& Steinbüchel, A. (2006a). MicroDiesel: Escherichia coli engineered for fuel production. Microbiology 152, 2529-2536.

Kalscheuer, R., Stöveken, T., Luftmann, H., Malkus, U., Reichelt, R. \& Steinbüchel, A. (2006b). Neutral lipid biosynthesis in engineered Escherichia coli: jojoba oil-like wax esters and fatty acid butyl esters. Appl Environ Microbiol 72, 1373-1379.

Kalscheuer, R., Stöveken, T., Malkus, U., Reichelt, R., Golyshin, P. N., Sabirova, J. S., Ferrer, M., Timmis, K. N. \& Steinbüchel, A. (2007). Analysis of storage lipid accumulation in Alcanivorax borkumensis: evidence for alternative triacylglycerol biosynthesis routes in bacteria. J Bacteriol 189, 918-928.

Katavic, V., Reed, D. W., Taylor, D. C., Giblin, E. M., Barton, D. L., Zou, J., MacKenzie, S. L., Covello, P. S. \& Kunst, L. (1995). Alteration of seed fatty acid composition by an ethyl methanesulfonate-induced mutation in Arabidopsis thaliana affecting diacylglycerol acyltransferase activity. Plant Physiol 108, 399-409.

Leman, J. (1997). Oleaginous microorganisms: an assessment of the potential. Adv Appl Microbiol 43, 195-243.

Marmur, J. (1961). A procedure for the isolation of deoxyribonucleic acid from microorganisms. J Mol Biol 3, 208-218.

McLeod, M. P., Warren, R. L., Hsiao, W. W., Araki, N., Myhre, M., Fernandes, C., Miyazawa, D., Wong, W., Lillquist, A. L. \& other authors (2006). The complete genome of Rhodococcus sp. RHA1 provides insights into a catabolic powerhouse. Proc Natl Acad Sci U S A 103, 15582-15587.

Olukoshi, E. R. \& Packter, N. M. (1994). Importance of stored triacylglycerols in Streptomyces: possible carbon source for antibiotics. Microbiology 140, 931-943.

Overhage, J., Priefert, H., Rabenhorst, J. \& Steinbüchel, A. (1999). Biotransformation of eugenol to vanillin by a mutant of Pseudomonas sp. strain HR199 constructed by disruption of the vanillin dehydrogenase ( $v d h)$ gene. Appl Microbiol Biotechnol 52, 820-828.

Packter, N. M. \& Olukoshi, E. R. (1995). Ultrastructural studies of neutral lipid localization in Streptomyces. Arch Microbiol 164, 420-427.

Pelicic, V., Reyrat, J. M. \& Gicquel, B. (1996). Generation of unmarked directed mutations in mycobacteria, using sucrose counter-selectable suicide vectors. Mol Microbiol 20, 919-925.

Quandt, J. \& Hynes, M. F. (1993). Versatile suicide vectors which allow direct selection for gene replacement in gram-negative bacteria. Gene 127, 15-21.
Ramakrishnan, L., Tran, H. T., Federspiel, N. A. \& Falkow, S. (1997). A $c r t B$ homolog essential for photochromogenicity in Mycobacterium marinum: isolation, characterization, and gene disruption via homologous recombination. J Bacteriol 179, 5862-5868.

Ratledge, C. (1989). Biotechnology of oils and fats. In Microbial Lipids, pp. 567-650. Edited by C. Ratledge \& S. G. Wilkinson. London: Academic Press.

Russell, N. J. \& Volkman, J. K. (1980). The effect of growth temperature and wax ester compositions in the psychrophilic bacterium Micrococcus cryophilus ATCC 15174. J Gen Microbiol 118, 131-141.

Sambrook, J., Fritsch, E. F. \& Maniatis, T. (1989). Molecular Cloning: a Laboratory Manual, 2nd edn. Cold Spring Harbor, NY: Cold Spring Harbor Laboratory.

Schlegel, H. G., Kaltwasser, H. \& Gottschalk, G. (1961). Ein Submersverfahren zur Kultur Wasserstoff oxydierender Bakterien: Wachstumsphysiologische Untersuchungen. Arch Mikrobiol 38, 209222 (in German).

Simon, R., Priefer, U. \& Pühler, A. (1983). A broad host range mobilization system for in vivo genetic engineering: transposon mutagenesis in gram negative bacteria. Biotechnology 1, 784-791.

Sirakova, T. D., Dubey, V. S., Deb, C., Daniel, J., Korotkova, T. A., Abomoelak, B. \& Kolattukudy, P. E. (2006). Identification of a diacylglycerol acyltransferase gene involved in accumulation of triacylglycerol in Mycobacterium tuberculosis under stress. Microbiology 152, 2717-2725.

Stahmann, K. P., Kupp, C., Feldmann, S. D. \& Sahm, H. (1994). Formation and degradation of lipid bodies found in the riboflavinproducing fungus Ashbya gossypii. Appl Microbiol Biotechnol 42, 121-127.

Steinbüchel, A. (1991). Polyhydroxyalkanoic acids. In Biomaterials, Novel Materials, pp. 123-213. Edited by D. Byrom. Basingstoke: Macmillan.

Steinbüchel, A. \& Valentin, H. E. (1995). Diversity of bacterial polyhydroxyalkanoic acids. FEMS Microbiol Lett 128, 219-228.

Stöveken, T., Kalscheuer, R., Malkus, U., Reichelt, R. \& Steinbüchel, A. (2005). The wax ester synthase/acyl coenzyme A: diacylglycerol acyltransferase from Acinetobacter sp. strain ADP1: characterization of a novel type of acyltransferase. J Bacteriol 187, 1369-1376.

Uthoff, S., Stöveken, T., Weber, N., Vosmann, K., Klein, E., Kalscheuer, R. \& Steinbüchel, A. (2005). Thio wax ester biosynthesis utilizing the unspecific bifunctional wax ester synthase/acylCoA : diacylglycerol acyltransferase of Acinetobacter sp. strain ADP1. Appl Environ Microbiol 71, 790-796.

Voss, I. \& Steinbüchel, A. (2001). High cell density cultivation of Rhodococcus opacus for lipid production at a pilot scale. Appl Microbiol Biotechnol 55, 547-555.

Wältermann, M. \& Steinbüchel, A. (2005). Neutral lipid-bodies in prokaryotes: recent insights into structure, formation and relationships to eukaryotic lipid depots. J Bacteriol 187, 3607-3619.

Wältermann, M. \& Steinbüchel, A. (2006). Wax ester and triacylglycerol inclusions. In Inclusions in Prokaryotes (Microbiology Monographs, vol. 1), pp. 137-166. Edited by J. M. Shively \& A. Steinbüchel. Heidelberg: Springer.

Wältermann, M., Luftmann, H., Baumeister, D., Kalscheuer, R. \& Steinbüchel, A. (2000). Rhodococcus opacus PD630 as a source of high-value single cell oil? Isolation and characterization of triacylgycerols and other storage lipids. Microbiology 146, 1143-1149.

Wältermann, M., Stöveken, T. \& Steinbüchel, A. (2006). Key enzymes for biosynthesis of neutral lipid storage compounds in prokaryotes: properties, function and occurrence of wax ester synthases/acylCoA : diacylglycerol acyltransferases. Biochimie 89, 230-242.

Edited by: M. Daffé 